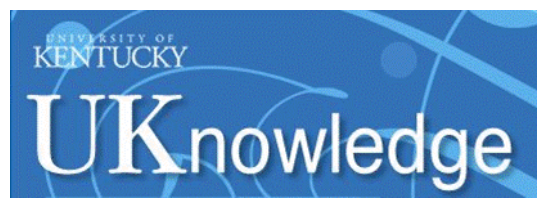

University of Kentucky

UKnowledge

2-19-2018

\title{
Formation of Two-Way Shape Memory Effect in NiTi Alloy Using Pulsed Laser Irradiation
}

\author{
Saidjafarzoda Ilhom \\ Western Kentucky University \\ Khomidkhodza Kholikov \\ Western Kentucky University \\ Peizhen Li \\ University of Kentucky, peizhen.li@uky.edu \\ Dovletgeldi Seyitliyev \\ Western Kentucky University \\ Zachary Thomas \\ Western Kentucky University
}

See next page for additional authors

Follow this and additional works at: https://uknowledge.uky.edu/me_facpub

Part of the Mechanical Engineering Commons

Right click to open a feedback form in a new tab to let us know how this document benefits you.

\section{Repository Citation}

Ilhom, Saidjafarzoda; Kholikov, Khomidkhodza; Li, Peizhen; Seyitliyev, Dovletgeldi; Thomas, Zachary; Roberts, Duvall; San, Omer; Karaca, Haluk E.; and Er, Ali O., "Formation of Two-Way Shape Memory Effect in NiTi Alloy Using Pulsed Laser Irradiation" (2018). Mechanical Engineering Faculty Publications. 49. https://uknowledge.uky.edu/me_facpub/49

This Conference Proceeding is brought to you for free and open access by the Mechanical Engineering at UKnowledge. It has been accepted for inclusion in Mechanical Engineering Faculty Publications by an authorized administrator of UKnowledge. For more information, please contact UKnowledge@lsv.uky.edu. 


\title{
Formation of Two-Way Shape Memory Effect in NiTi Alloy Using Pulsed Laser Irradiation
}

\author{
Digital Object Identifier (DOI) \\ https://doi.org/10.1117/12.2290276
}

\section{Notes/Citation Information}

Published in Proceedings of SPIE, v. 10520, Laser-based Micro- and Nanoprocessing XII, article 105200V, p. 1-7.

(C) 2018 SPIE. One print or electronic copy may be made for personal use only. Systematic reproduction and distribution, duplication of any material in this paper for a fee or for commercial purposes, or modification of the content of the paper are prohibited.

Saidjafarzoda Ilhom, Khomidkhodzha Kholikov, Peizhen Li, Dovletgeldi Seyitliyev, Zachary Thomas, Duvall Roberts, Omer San, Haluk E. Karaca, and Ali O. Er, "Formation of two-way shape memory effect in NiTi alloy using pulsed laser irradiation," Proc. SPIE 10520, Laser-based Micro- and Nanoprocessing XII, 105200V (February 19, 2018). DOI: https://doi.org/10.1117/12.2290276

The copyright holder has granted the permission for posting the article here.

\section{Authors}

Saidjafarzoda Ilhom, Khomidkhodza Kholikov, Peizhen Li, Dovletgeldi Seyitliyev, Zachary Thomas, Duvall Roberts, Omer San, Haluk E. Karaca, and Ali O. Er 


\section{Formation of two-way shape memory effect in NiTi alloy using pulsed laser irradiation}

Saidjafarzoda Ilhom, Khomidkhodzha Kholikov, Peizhen Li, Dovletgeldi Seyitliyev, Zachary Thomas, et al.

Saidjafarzoda Ilhom, Khomidkhodzha Kholikov, Peizhen Li, Dovletgeldi Seyitliyev, Zachary Thomas, Duvall Roberts, Omer San, Haluk E. Karaca, Ali O. Er, "Formation of two-way shape memory effect in NiTi alloy using pulsed laser irradiation," Proc. SPIE 10520, Laser-based Micro- and Nanoprocessing XII, 105200V (19 February 2018); doi: 10.1117/12.2290276 


\title{
Formation of two-way shape memory effect in NiTi alloy using pulsed laser irradiation
}

\author{
Saidjafarzoda Ilhom ${ }^{\mathrm{a}}$, Khomidkhodza Kholikov ${ }^{\mathrm{a}}$, Peizhen Li ${ }^{\mathrm{b}}$, Dovletgeldi Seyitliyev ${ }^{\mathrm{a}}$, Zachary \\ Thomas ${ }^{\mathrm{a}}$, Duvall Roberts ${ }^{\mathrm{a}}$, Omer San ${ }^{\mathrm{c}}$, Haluk E. Karaca ${ }^{\mathrm{b}}$, Ali O. Er ${ }^{\mathrm{a}^{*}}$. \\ ${ }^{a}$ Department of Physics and Astronomy, Western Kentucky University, 1906 College Heights \\ Blvd., Bowling Green, KY, USA 42101; 'bepartment of Mechanical Engineering, University of \\ Kentucky, RGAN 210, Lexington, KY USA 40506-0503; 'School of Mechanical and Aerospace \\ Engineering, Oklahoma State University, Stillwater, OK USA 74078
}

\begin{abstract}
We report an advanced laser imprinting technique with low cost, quick and minimal environmental impact. Microindents were obtained on $\mathrm{Ni}_{50} \mathrm{Ti}_{50}$ (at. \%) SMAs using an Nd:YAG laser with $1064 \mathrm{~nm}$ wavelength at $10 \mathrm{~Hz}$. Laser pulses at selected fluences were focused on the NiTi surface and generated pressure pulses of up to a few GPa. Scanning electron microscope (SEM) and optical microscope images showed that surface patterns with tailorable sizes can be obtained, where the depth of the patterns increased with laser power and irradiation time. Upon heating, the maximum depth recovery ratio of $30 \%$ was observed. Recovery ratio decreased and stayed around $15 \%$ when the amount of time and thus the indent depth was increased. Laser-induced shock wave propagation inside the material was simulated and the stress wave was shown to closely follow the rise time of the laser pulse to its peak value and initial decay. Rapid attenuation and dispersion of the stress wave were observed.
\end{abstract}

Keywords: laser-shockwave, laser plasma, microindents, patterning, shape recovery, NiTi, simulation

\section{INTRODUCTION}

Micro/nanoscale patterning onto metallic components has gained great significance in aerospace, microelectronics, and biomedical sectors [1-4]. Lasers have opened new ways to fabricate periodic structures directly on polymers, ceramics, metals, and more dimensional surface patterns on variety of metallic components in a wide range of industries $[1,2,5-8]$. Surface patterning by lasers is flexible, environmentally friendly, remote and contactfree, precise, scalable, and doesn't involve any etching process $[5,9]$.

In laser-assisted patterning, a high energy laser pulse generates high amplitude plasma pressure (>1 GPa) that creates a strong shock wave, and consequently, forming three-dimensional microindents [10-13]. Even a single laser pulse can create pattern once the power density exceeds the certain threshold. Laser shock wave imprinting offers variety of advantages where any template can be transferred onto desired surface with high fidelity. Patterning of the predetermined template is highly scalable and the size and shape of the template allows precise control. These characteristics makes laser-induced shock wave assisted imprinting highly desirable in patterning of functional devices especially in aerospace applications.

During laser-assisted patterning process, parameters such as the laser wavelength, energy density, repetition rate, pulse duration, spot size on target, target composition, and surface quality in addition to laser-produced plasma properties, such as degree of ionization and temperature of plasma species play important roles [14, 15]. As the shockwave travels through substrate, plastic deformations occur to a depth where the peak pressure drops below the Hugoniot elastic limit. Amount of deformation depends on the pressure. Therefore, it is important to estimate the peak pressure which is given by

$$
P(G P a)=0.01\left[\frac{Z\left(\mathrm{gcm}^{-2} \mathrm{~s}^{-1}\right) I_{0}\left(G W / \mathrm{cm}^{2}\right) \delta}{2 \delta+3}\right] x^{1 / 2}
$$

*ali.er@wku.edu; phone 1270 745-6202; physics.wku.edu/ali.er/

Laser-based Micro- and Nanoprocessing XII, edited by Udo Klotzbach, Kunihiko Washio, Rainer Kling, Proc. of SPIE Vol. 10520, 105200V · (c) 2018 SPIE · CCC code: 0277-786X/18/\$18 · doi: 10.1117/12.2290276 
where $\mathrm{I}_{\mathrm{o}}$ is the incident laser power density, $\mathrm{P}$ is the pressure, and $\mathrm{Z}$ is the reduced acoustic impedance between a target and medium, and $\delta$ is the efficiency of plasma material interaction [16].

SMAs are a class of active materials that can change their shape reversibly with a change in temperature, stress or magnetic field. Among SMA applications, morphing at micro and macro scales attracts considerable interest $[17,18]$. For instance, surface roughness and texture can drastically alter the characteristics of turbulent flow, and, thus, the drag and friction forces exerted on the surface of a moving object in a fluid [19, 20]. It has been reported that the "riblets" on the shark skin can reduce the wall shearing stress or wall friction up to $10 \%$ while many surface structures are known to increase friction and drag force [21,22]. Consequently, it may be possible to optimize the flight characteristics of moving objects by reversibly controlling surface roughness and texture. For micro-morphing, shape memory surfaces can be produced by embedding SMAs into aircraft structure and forming "hybrid structures" [23-25]. The temperature change (e.g. triggered by electrical current) will activate SMAs and surface geometry will change upon phase transformation where transformed surfaces could generate very different drag or friction forces that can be optimized for aircraft operation. SMAs can produce reversible surface protrusions based on the phase change between martensite and austenite. Thermal cycling which may be repeated indefinitely, results in a 'bumpy' or flat surface $[25,26]$.

In this study, we have patterned NiTi shape memory alloys with different templates. We have also analyzed the changes in depth of the generated patterns on NiTi SMA with respect to the laser energy density and report optimum conditions to generate smooth patterns with the highest depth.

\section{EXPERIMENTAL METHODS}

The SMA alloys were firstly electrical-discharge machined to a circular plate with a diameter of $10 \mathrm{~mm}$ and thickness of $1 \mathrm{~mm}$. The surface roughness of samples were reduced to $0.05 \mu \mathrm{m}$ in five steps by using Buehler EcoMet 250 Grinder-Polisher with an AutoMet 250 Power head. Transformation temperatures were determined by using a Perkin-Elmer Pyris 1 differential scanning calorimeter (DSC). The martensite and austenite start and finish temperatures $\left(\mathrm{M}_{\mathrm{s}}, \mathrm{M}_{\mathrm{f}}, \mathrm{A}_{\mathrm{s}}\right.$, and $\mathrm{A}_{\mathrm{f}}$, respectively) are $78{ }^{\circ} \mathrm{C}, 45^{\circ} \mathrm{C}, 85{ }^{\circ} \mathrm{C}, 122{ }^{\circ} \mathrm{C}$. Samples were patterned by the nanosecond Nd:YAG pulsed laser Continuum Surelite II. Laser has a fundamental wavelength of $1064 \mathrm{~nm}$, pulse width of 5 nanosecond, $10 \mathrm{~Hz}$ repetition rate and Gaussian shape with $6 \mathrm{~mm}$ diameter of unfocused beam (measured at $1 / \mathrm{e}^{2}$ ). The experimental setup for pulsed laser assisted shock wave imprinting in our lab is shown in Figure 1.

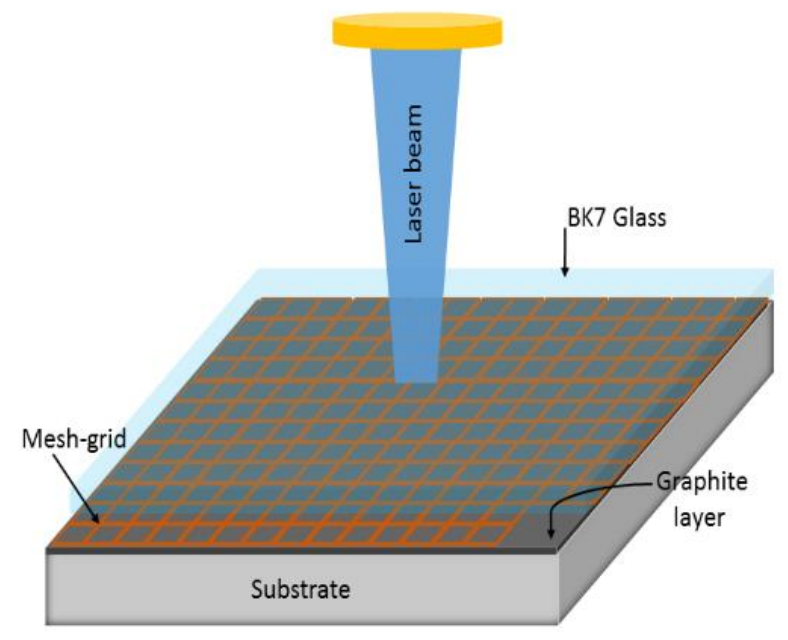

Figure 1. Illustration of laser shockwave imprinting on SMA substrate.

After the patterning, copper grid was peeled off and the graphite layer was washed off by acetone. Morphological properties of the surface were investigated by SEM (Jeol 6510LV) and a light microscope (Keyence VHX500F) and depth recovery were measured and analyzed by a laser profiler (Zygo, NewView 7300). 


\section{RESULTS}

Laser-induced shock wave can successfully transfer almost any template on any material as long as the right parameters are used. For example, successful imprinting of (a) hexagonal and (b) square copper grid onto aluminum sample by a single pulse with energy of $6.4 \mathrm{~J} / \mathrm{cm}^{2}$ is shown in Figure 2. Aluminum was obtained from commercially available source. After irradiation, patterned surface is visible with SEM. These patterns were generated under the outlined area of copper grid which shows the ablation of the copper and due to the punch of the copper grid onto the sample. Figure 2 shows that resulting pattern has high fidelity. Patterning of the predetermined template is highly scalable where size and shape of the template allows precise control. The laser beam can be scanned over the surface to produce the desired pattern at large scale. By changing the number of pulses at each point and laser fluence, depth of the pattern can be controlled precisely.
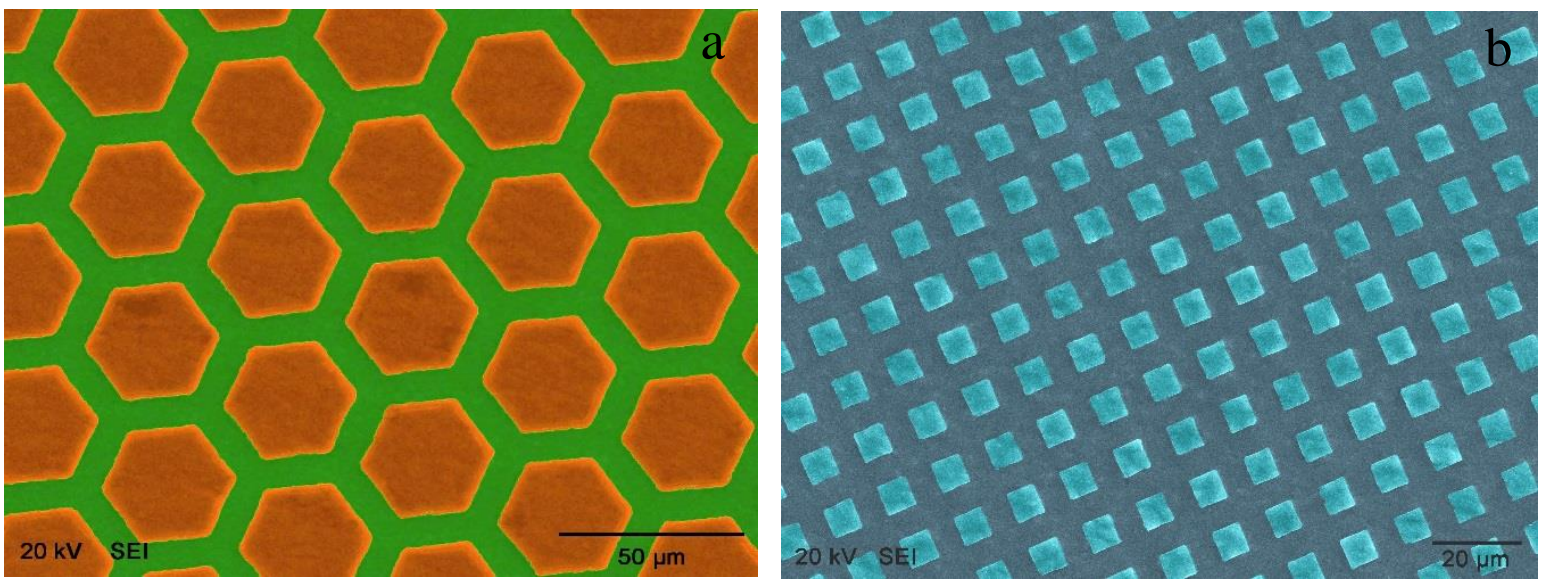

Figure 2. SEM images of (a) hexagonal (b) square copper mesh grid after irradiation with laser energy of $6.4 \mathrm{~J} / \mathrm{cm}^{2}$.

SMAs show stress-induced recovery, which is mainly obtained by nanoindentation, a technique where indenter is pushed against the material to promote large-stress induced transformation [27-30]. In this work, we have used laser surface imprinting as an alternative to nanoindentation. Figure 3(a) shows the patterning on the NiTi shape memory alloys when $2 \mathrm{~J} / \mathrm{cm}^{2}$ is used. The square grid has 300 lines/inch, hole width of $58 \mu \mathrm{m}$, pitch width of $83 \mu \mathrm{m}$, and bar width of $25 \mu \mathrm{m}$ with diameter of $3 \mathrm{~mm}$ and thickness of $20 \mu \mathrm{m}$. The patterns were obtained with a single pulse. Shape memory alloys recover their previously defined shapes after deformation once they are heated to a certain
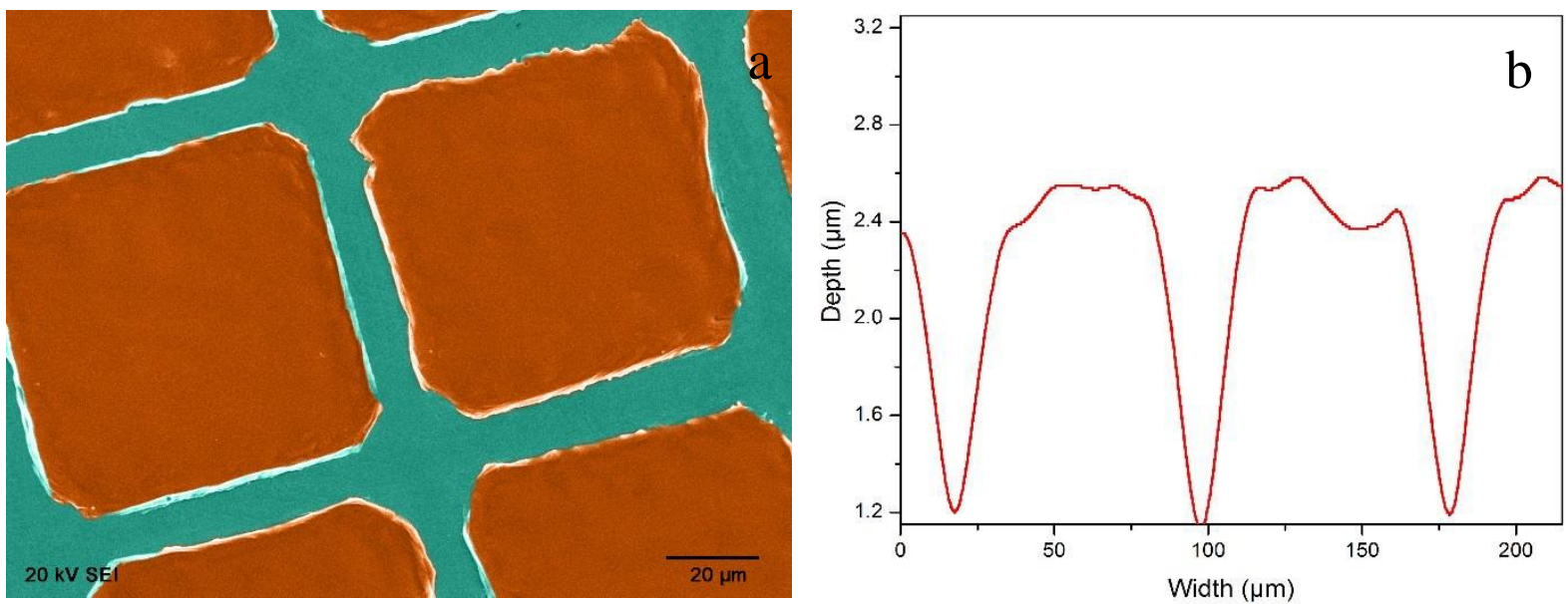

Figure 3. (a) SEM image of as-created patterns and (b) linear height profile of patterns on NiTi shape memory alloys at 2.0 $\mathrm{J} / \mathrm{cm}^{2}$ energy.

temperature. This stress induced martensitic phase transformation phenomenon is known as shape memory recovery 
effect (SME) [31, 32]. Upon deformation or processing, the reversible two-way shape memory effect (TWSME) could be obtained. Figure 3(b) shows the line scan of the patterned surface obtained with $2 \mathrm{~J} / \mathrm{cm}^{2}$. The average depth of the indent is around $1.5 \mu \mathrm{m}$. As expected, patterns that were generated on the surface have the similar dimensions as the copper grid.
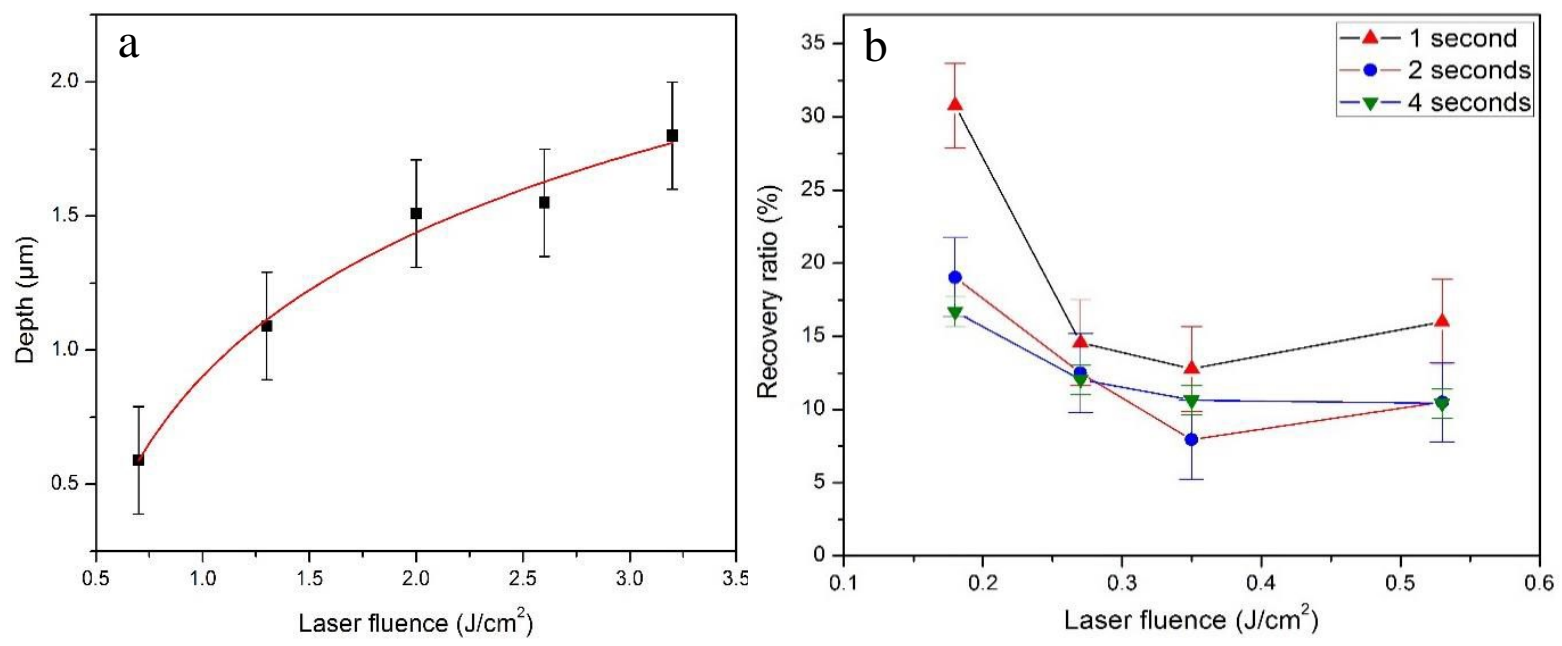

Figure 4. (a) Indent depth and (b) recovery ratio of patterns on NiTi shape memory alloys at different laser fluences.

In order to find the optimum laser parameters to achieve the highest and the smoothest patterns with high recovery ratio, pattern with different depths was obtained by changing laser energy density between $0.7-3.2 \mathrm{~J} / \mathrm{cm}^{2}$. Figure 4(a) shows the change in depth of patterns generated on the surface with respect to laser energy density. These depth measurements are the average depth of 8 different points from 3 separate samples.

The recovery of patterned SMA surfaces was investigated by heating the samples to $160{ }^{\circ} \mathrm{C}$ and measuring their depth profile and maximum depth. Linear depth profiles were measured at 4 different positions to get better reliability. Upon the determination of maximum indent depth at $160^{\circ} \mathrm{C}$, the recovery rate, difference between hot and cold state over cold state, was calculated as a function of energy and duration. As shown in Figure 4(b), our initial results show that recovery ratio of $30 \%$ can be obtained when the laser energy density was $0.18 \mathrm{~J} / \mathrm{cm}^{2}$ and irradiation time 1 second with total 10 pulses. The recovery ratio subsequently decreased to $15 \%$ with increasing depth.

It is well known that lasers can produce high temperature and high pressure when absorbed by a material. In most of the practical applications, it is critical to determine the heat transfer mechanism for accuracy of laser processing. To better understand the pressure propagation, a numerical simulation of pressure evolution in copper irradiated by a nanosecond pulsed laser $(1064 \mathrm{~nm}$ wavelength, $10 \mathrm{~Hz}, 150 \mathrm{~mJ}, 3 \mathrm{~mm}$ beam diameter, $5 \mathrm{~ns}$ pulse width) was conducted using the fifth-order weighted essentially non-oscillatory finite volume method [33,34]coupled with a Mie-Gruneisen model [35]. The energy flux due to the laser irradiation is modeled as a volumetric heat source in the energy equation. Beer's law with a Gaussian distribution describes the absorption of laser energy

$$
Q(x, y, t)=I_{0}(1-R) \alpha e^{\left(-\alpha\left(y_{S}-y\right)-\frac{\left(x-x_{S}\right)^{2}}{r_{0}^{2}}-\frac{t^{2}}{t_{0}^{2}}\right)}
$$

where $\left(x_{s}, y_{s}\right)$ is the surface coordinates of the laser beam center and $z=y_{s}-y$ measures the depth from the surface. Here, $I_{0}, R, \alpha, t_{0}$ and $r_{0}$ are laser energy intensity, reflectance, absorption coefficient, pulse width and the beam radius, respectively. In this study, the absorption coefficient is $8.3 \times 10^{7} \mathrm{~m}^{-1}$ and the energy transferred by radiation is not considered. Figure 5 illustrates the surface pressure and temperature evolution computed at $\left(x_{s}, y_{s}\right)$ for $150 \mathrm{~mJ} / \mathrm{pulse}$.

Our preliminary result shows that pressure is strongly dependent on the value of total incident laser energy density and the peak pressure value increased with laser energy density. The hydrostatic pressure of $>8 \mathrm{GPa}$ and temperature of $>6000 \mathrm{~K}$ could be generated when laser energy intensity of $2 \mathrm{~J} / \mathrm{cm}^{2}$ laser pulse is used. 


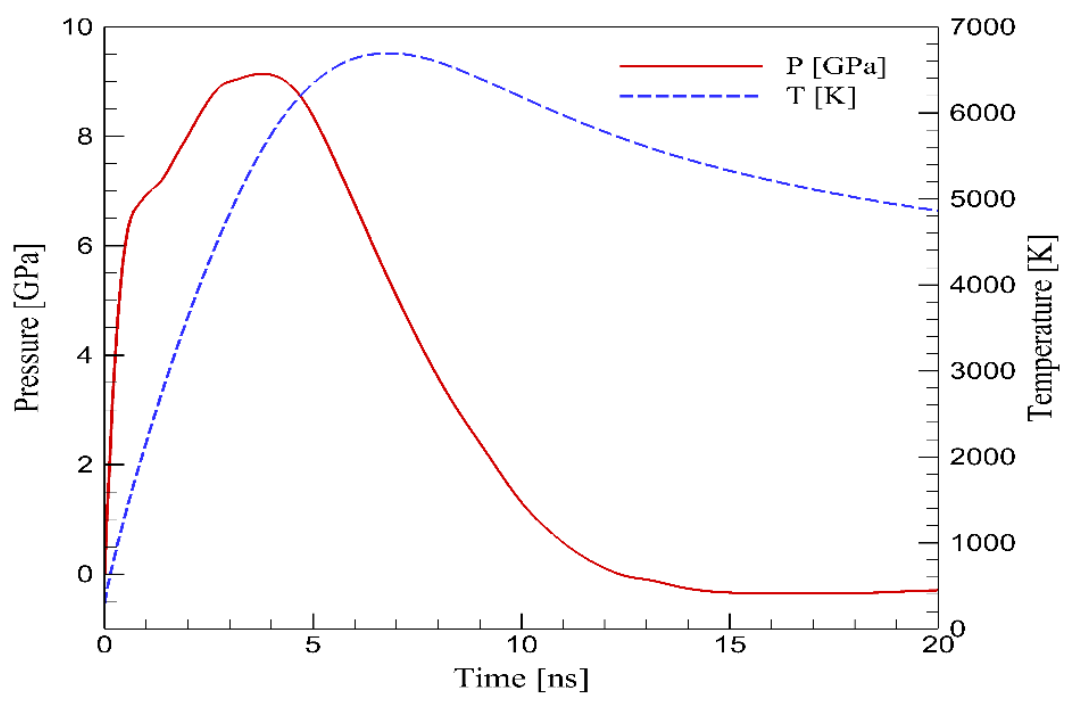

Figure 5. Time evolution of surface pressure and temperature for $2 \mathrm{~J} / \mathrm{cm}^{2}$ laser energy density.

\section{CONCLUSION}

In this report, we have shown successful patterning of NiTi shape memory alloys by an advanced direct imprinting method using nanosecond laser pulses with low cost, quick, and low environmental impact. Square templates were successfully imprinted on NiTi. Laser energy was shown to play an important role for surface patterning. Time evolution of laser-induced shock wave and temperature was also simulated, which showed that the pressure wave closely follows the laser pulse rise time and attenuates as the time advances. Laser-induced shock wave imprinting appears to be strong candidate to replace nanoindentation to obtain two-way shape memory effect. 


\section{REFERENCES}

[1] Sugioka, K., Y.Cheng., Ultrafast lasers-reliable tools for advanced materials processing, Light Sci. App. 3, E149-12 (2014).

[2] Fei, X., D.S. Grummon, C. Ye, G.J. Cheng and Y.-T. Cheng., Surface form memory in niti shape memory alloys by laser shock indentation, J. Mater. Sci. 47, 2088-2094 (2012).

[3] Ozbay, E., Plasmonics: merging photonics and electronics at nanoscale dimensions, Science 311(5758), 189-193 (2006).

[4] Shen, N., H. Ding, R. Browers, Y. Yu, C.N. Pence, I.T. Ozbolat, C.M. Stanford, Surface micropatterning of pure titanium for biomedical applications via high energy pulse laser peening, Journal Of Micro And NanoManufacturing, 3(1), 011005 (2015).

[5] Ye, C., G. Y. Cheng, Scalable patterning on shape memory allow by laser shock assisted imprinting, Appl. Surf. Sci. 258, 10042-10046 (2012).

[6] Gao, H., Y. Hu, Y. Xuan, J. Li, Y. Yang, R.V. Martinez, C. Li, J. Luo, M. Qi, G.J. Cheng, Large-scale nanoshaping of ultrasmooth 3d crystalline metallic structures, Science 346(6215),1352-6 (2014).

[7] Brady, S., B. Aubert, L. Berthe, P. Combis, D. Hebert, E. Lescoute, J.L Rullier, L. Videau, Numerical study of laser ablation on aluminum for shock-wave applications: Development of a suitable model by comparison with recent experiments, opt. eng. 56(1), 011014-011014 (2017).

[8] Wang, Z., G. Feng, J. Han, S. Wang, R. Hu, G. Li, S. Dai, S. Zhou, Fabrication of microhole arrays on coated silica sheet using femtosecond laser, Opt. Eng. 55(10), 105101-105101 (2016).

[9] Fabbro, R., J. Fournier, P. Ballard, D. Devaux, J. Virmont, Physical study of laser-produced plasma in confined geometry, J. Appl. Phys. 68, 775-784 (1990).

[10] Clauer, A. H., J.H. Holbrook, B.P. Fairand, Effects of laser induced shock waves on metals, In Shock Waves And High-Strain-Rate Phenomena In Metals, Pp. 675-702, Springer Us, 1981.

[11] Gehring, F., M. Boustie, F. Touchard, L. Chocinski-Arnault, S. Guinard, S. Senani, Use of laser shock waves to test piezochromic coatings for impact detection, Opt. Eng. 56(1), 011023-011023 (2017).

[12] Er, A.O., J. Chen., J. Tang, P.M. Rentzepis, "Coherent acoustic wave oscillations and melting on $\operatorname{Ag}(111)$ surface by time resolved x-ray diffraction," Appl Phys Lett, 100, 51910-51915, (2012).

[13] Ilhom, S., D. Seyitliyev, K. Kholikov, Z. Thomas, O.E. Ali, P. Li, H.E. Karaca, and O. San, "Laser Shock Wave-Assisted Patterning on NiTi Shape Memory Alloy Surfaces," Shape Memory and Superelasticity, pp.1-8 (2018).

[14] Berthe, L., R. Fabbro, P. Peyre, E. Bartnicki, Wavelength dependent of laser shock-wave generation in the water-confinement regime, J. Appl. Phys. 85, $7552-7555$ (1999).

[15] Amoruso, S., R. Bruzzese, N. Spinelli, And R. Velotta, Characterization of laser-ablation plasmas, Phys. B: At. Mol. Opt. Phys. 32, R131-R172, (1999).

[16] Peyre, P., L. Berthe, X. Scherpereel, R. Fabbro, E. Bartnicki, Experimental study of laser-driven shock waves in stainless steels, J. Appl. Phys. 84, 5985-5992 (1998).

[17] Hartl D.J., and D. C. Lagoudas, Aerospace applications of shape memory alloys, Proc. Inst. Mech. Eng. Part G, J. Aerospace Eng. 221, 535-552 (2007).

[18] Gonzalez, L., Morphing wing using shape memory alloy: a concept proposal, Final Research Paper In (2005).

[19] Thill, C., J. Etches, I. Bond, K. Potter, P. Weaver, Morphing skins, Aeronaut. Journal 112, 117-139 (2008).

[20] Jimenez, J., Turbulent flows over rough walls, Annual Rev. Fluid Mech. 36, 173-196 (2004).

[21] Bechert, D.W., M. Bruse, and W. Hage, Experiments with three-dimensional riblets as an idealized model of shark skin, Exp. Fluids 28, 403-412 (2000).

[22] Klocke, F., B. Feldhaus, and S. Mader, Development of an incremental rolling process for the production of defined riblet surface structures, Prod. Eng. Res. Develop. 1, 233 (2007).

[23] Cheng, Y.-T., D. S. Grummon, Indentation in shape memory alloys. micro and nano mechanical testing of materials and devices, Ed. F.Q. Yang and J.C.M. Li. Springer. 71-86. (2008).

[24] Zhang, Y., Y.-T. Cheng and D. S. Grummon, Shape memory surfaces, Appl. Phys. Lett. 89, 41912-3 (2006).

[25] Zang, Y., Y.-T. Cheng, and D. S. Grummon, Two-way indent depth recovery in a niti shape memory alloy, Appl. Phys. Lett. 88, 131904-3 (2006). 
[26] Birnbaum, A.J., Y. L. Yao, The effects of laser forming on niti superelastic shape memory alloys, J. Manuf. Sci. Eng. 132, 041002-8 (2010).

[27] Li, P., H.E. Karaca, Y.T. Cheng, "Rapid Characterization of Local Shape Memory Properties through Indentation. Scientific reports, 7, 14827 (2017).

[28] Li, P., H.E. Karaca, Y.I. Chumlyakov, "Orientation dependent compression behavior of Co35Ni35Al30 single crystals," J Alloys Compd, 718, 326-334, (2017).

[29] Turabi, A. S., H.E. Karaca, H. Tobe, B. Basaran, Y. Aydogdu, Y.I. Chumlyakov, Shape memory effect and superelasticity of nimncoin metamagnetic shape memory alloys under high magnetic field, Script. Mater. 111, 110-113 (2016).

[30] Karaca, H. E., B. Basaran, I. karaman, Y.I. Chumlyakov, Stress-induced martensite to austenite phase transformation in $\mathrm{Ni}_{2} \mathrm{MnGa}$ magnetic shape memory alloys," Smart Mater. Struct. 21(4), 045011 (2012).

[31] Karaca, H. E., E. Acar, H. Tobe, S.M. Saghaian, NiTiHf-based shape memory alloys, Mater. Sci. Technol. 30(13), 1530-1544 (2014).

[32] Li, P., H.E., Karaca, Y.T. Cheng, "Spherical indentation of NiTi-based shape memory alloys," Journal of Alloys and Compounds, 651, 724-730, (2015)..

[33] San, O., and K. Kara, Evaluation of riemann flux solver for weno reconstruction schemes: KelvinHelmholtz instability, Comput. Fluids. 117, 24-41 (2015).

[34] Titarev, V.A., E. Romenski, E.F. Toro, MUSTA-type upwind fluxes for non-linear elasticity, Int. J. Numer. Meth. Engnr. 73(7), 897-926 (2008).

[35] Mehmandoust, B., A.R Pishevar, An Eulerian particle level set method for compressible deforming solids with arbitrary EOS, Int. J. Num. Meth. Eng. 79(10), 1175-1202 (2009). 